\title{
Türkiye'de ortopedi ve travmatoloji asistanı olmak
}

\author{
Being an orthopaedics and traumatology resident in Turkey
}

\author{
Safa Gürsoy
}

Ankara Atatürk Eğitim ve Araştırma Hastanesi, Ortopedi ve Travmatoloji Kliniği, Ankara

\begin{abstract}
Dünyada ve ülkemizde son yıllarda asistanlık eğitiminin iyileştirilmesi ve geliştirilmesi amacıyla, ulusal ve uluslararası meslek örgütleri önderliğinde çalışmalar sürdürülmektedir. Ülkemizde ortopedi ve travmatoloji asistan eğitimi alanındaki bu çalışmalar, özellikle, kuruluş amacı Türkiye'de ortopedi ve travmatoloji uzmanlık eğitiminin kalitesinin yükseltilmesi olan Türk Ortopedi ve Travmatoloji Eğitim Konseyi ve Türk Ortopedi ve Travmatoloji Birliği Derneği tarafından yürütülmektedir. $\mathrm{Bu}$ derlemede, ortopedi asistan eğitimi konusunda, yurt dışındaki örnek uygulamalar ve ülkemizde son yıllardaki yapılan çalışmalar, Türk Ortopedi ve Travmatoloji Birliği Derneği - Asistan ve Genç Uzman Hekimler Konseyi'nin gerçekleştirdiği yüksek katılımlı asistan anketinin sonuçlarına da yer vererek ele alınmıştır.
\end{abstract}

Anahtar sözcülkler: asistanlık eğitimi; eğitimin standardizasyonu; simülasyon laboratuvarları; yurtdışı eğitim olanakları
In recent years, efforts are underway in order to improve and develop the residency training throughout the world and in our country, under the leadership of national and international profession organizations. These efforts in orthopaedics and traumatology residency training are carried out especially by the Turkish Orthopaedics and Traumatology Education Council and the Turkish Society of Orthopaedics and Traumatology. The main purpose of both organizations is to promote the education quality of the orthopaedics and traumatology residency training in Turkey. In this review, sample applications abroad and recent studies in our country were discussed with reference to high-participation resident survey which was performed by the Turkish Society of Orthopaedics and Traumatology Resident and Young Attendants Council.

Key words: residency training; standardization of training; simulation labs; overseas training opportunities
T ıpta uzmanlık eğitimi, uzmanlık eğitimi öğrencisine, rehberlik ve gözetim altında sunulmak üzere düzenlenmiş olan eğitim programıdır. Bu program ile bir yandan asistanların kişisel ve mesleki gelişimi diğer yandan da hastaların güvenli ve uygun sağlık hizmeti almaları sağlanır.

İçinde bulunduğumuz yüzyılda gelişen teknoloji ve iletişim becerileri sonucunda, her bilim dalında olduğu gibi, tıpta da bilgi birikimi ve hasta hakları bakımından uzun bir sıçrama gerçekleşmiştir. Artan bu bilgi birikimi nedeniyle, gelişen dünyaya ayak uydurabilmek için tüm tıp dallarında, tıp öğrencisi ve asistan eğitimi konularında birtakım değişikliklerin yapılması zorunlu hale gelmiştir.

Dünyanın pek çok ülkesinde lisans, asistanlık ve sürekli tıp eğitimi alanlarında iyileştirme çalışmaları sürdürülmektedir. Bu bağlamda Dünya Tıp Eğitimi Federasyonu tarafindan uzmanlık eğitimi için asgari standartları belirlemeye yönelik bazı çalışmalar yapılmaktadır. ${ }^{[1-4]}$

Ülkemizde de son yıllarda uzmanlık eğitiminde bir değişim ve iyileştirme uğraşı söz konusudur. Aynı çalışmalar ortopedi ve travmatoloji alanında da görülmektedir. Türkiye'de bu çalışmalara başta Türk Ortopedi ve Travmatoloji Eğitim Konseyi (TOTEK) ve Türk Ortopedi ve Travmatoloji Birliği Derneği (TOTBiD) öncülük etmektedir. Bu çalışmalar yapılırken "ortopedinin geleceğinin asistan eğitim programlarının başarısına bağlı" olduğu gerçeği göz önünde tutulmalıdır.

Bu yazıda, Türkiye'de asistanlık eğitiminin tanımı ve durumu, eğitim olanakları ve asistanlık eğitiminin geliştirilmesi için yapılan çalışmalar, yurt dışındaki örneklerle karşılaştırılarak ve TOTBID-AGUH'nin gerçekleştirdiği yüksek katılımlı değerlendirme anketine de yer verilerek ele alınmıştır.

- İletişim adresi: Dr. Safa Gürsoy, Ankara Atatürk Eğitim ve Araştırma Hastanesi, Ortopedi ve Travmatoloji Kliniği, Bilkent, Çankaya, Ankara Tel: 0505 - 4896632 e-posta: safagursoy@yahoo.com

- Geliș tarihi: 24 Ekim $2014 \quad$ Kabul tarihi: 24 Ekim 2014 


\section{TÜRKIYE'DE ASISTANLIK EĞiTiMi VE MEVZUATI}

Dahili ve Cerrahi uzmanlıklarda ileri eğitim fırsatı sunan asistanlık, ilk olarak 19. yüzyılın sonlarında özel ilgi alanlarında uzmanlaşma şeklinde resmi olmayan programlar olarak ortaya çıkmıştır. illk resmi asistanlık programı Sir William Osler ve William Stewart Halsted tarafindan Johns Hopkins Hastanesi'nde kurulmuştur. Asistanlık programları, 20. yüzyılın başlarında daha başka yerlerde de açılarak resmileşmiş ve kurumsal bir hal almıştır.

Türkiye'de uzmanlık eğitimi, asistan hekimlerin görev tanımı, hak ve sorumlulukları, Yüksek Öğrenim Kurumu tarafından 'Tıpta Uzmanlık Tüzüğü' ile düzenlenmiştir. Bu mevzuata göre asistan hekim 'Kurumlarındaki kadro ünvanı ne olursa olsun, tıpta uzmanlık ana dallarından birinde uzman olarak yetiştirilmek amacıyla, bu Yönetmelik ve ilgili mevzuat hükümleri çerçevesinde eğitim ve öğrenim gören, araştırma ve uygulama yapan tabip" olarak tanımlanmıştır. ${ }^{[5]}$

Türkiye'de ortopedi ve travmatoloji asistanlık eğitimi beş yıldır. 18 Temmuz 2009 tarihli Resmi Gazetede yayımlanan yönetmelik değişikliği neticesinde birçok ana dalda eğitim süresi kısaltılmıştır. Ancak ortopedi asistanlığının süresi değiştirilmemiştir.

Türkiye'de Üniversite Tıp Fakülteleri ve Sağlık Bakanlığı'na bağlı hastaneler olmak üzere toplam 100 civarında eğitim hastanesinde 800 'ün üzerinde ortopedi ve travmatoloji uzmanlık öğrencisinin eğitimi sürdürülmektedir.

\section{EĞiTTMIN STANDARDIZASYONU}

Amerika Birleşik Devletleri'nde ortopedi eğitim programlarına 1934 yılından beri American Board of Orthopaedic Surgery (ABOS) yol göstermektedir. ${ }^{[6]}$ Buna rağmen eğitim içerikleri stardart olmamakla birlikte, programlar arasında birçok farklılık bulunmaktadır. Ortopedi eğitim programlarının üç temel amacı bulunmaktadır. 1) Ortopedik cerrahi alanında yaygın hastalıklar ve durumlar hakkında eğitim, 2) ilgili temel ve klinik bilimler ile ilgili eğitim, 3) ortopedik cerrahi teknik ve prosedürler ile ilgili eğitim. Üçüncü amaç, cerrahinin ayrıntıları, cerrahi ekipmanlar ve teknik becerilerin pratiği ile ilgili bilgileri kapsar. Bu üç amaç, asistanların cerrahi karar verme yeteneği kazanmasına hizmet etmektedir.

Türkiye'de ortopedi ve travmatoloji asistanlık eğitiminin standardizasyonu başta TOTEK ve TOTBID tarafından sağlanmaya çalışılmaktadır. Kuruluş temel amacı Türkiye'de "Ortopedi ve Travmatoloji Uzmanlık Eğitimi ve hekimliğinin" kalitesinin yükseltilmesi ve eğitim birimlerinin kendi aralarındaki standardizasyonunun sağlanması olan TOTEK, bu amaca yönelik olarak tıpta uzmanlık tüzügünün 'asistanın değerlendirmesi' başlıklı 24. maddesi çerçevesinde uzmanlık öğrencisinin eğitimi boyunca gerçekleştirdiği tüm faaliyetleri içeren bir belge olan asistan karnesini düzenlemiştir. Asistan eğitim karnesinin etkili olarak kullanılması ile standart bir eğitim alma şansının ortaya çıkacağına inanılmaktadır. Altıncı dönem TOTEK yönetim kurulu tarafindan başlatılan, TOTBID ve Türk Tabipleri Birliği birlikteliği ile gerçekleştirilen kurum ziyaretleri de yine bu amaca hizmet etmektedir. Ancak kurum ziyaretleri gönüllük esasına göre yapılmaktadır. Asistan karnelerinin tek yaptırımı ve kontrolü ise uzmanlık sınavı öncesi adayın jüriye belgeyi teslim etmesi şeklinde olmaktadır. Eğitim süresi içerisinde karnenin takibi ve anında müdahale kliniğin eğitim sorumlusuna bırakılmaktadır. Türk Ortopedi ve Travmatoloji Birliği Derneği - Asistan ve Genç Uzman Hekimler Konseyi (TOTBID-AGUH)'nin yaptığı ankette ise "Asistan karnesi var mı?/uygulanıyor mu?" sorusuna "Evet" cevabı \%30 düzeylerinde kalmıştır. ${ }^{[7]}$

TOTBiD'e bağlı olarak 2011 yılında kurulmuş genç ortopedistler organizasyonu olan TOTBID-AGUH'nin de amaçlarından biri ortopedi asistan eğitiminin standardizasyonudur. AGUH oluşturduğu sosyal platformlar sayesinde ortopedi asistanlarının arasındaki iletişimi güçlendirerek, ortak bir dil oluşturulmasını hedeflemektedir.

AGUH ayrıca, takipçisi olduğu ve yönlendirdiği yurtdışı eğitim olanakları ve kurduğu uluslararası işbirlikleri ile ortopedi eğitiminin standartlarının yükseltilmesine katkı sağlamaktadır. Bizler Türkiye'deki ortopedi ve travmatoloji asistanları olarak AGUH'nin felsefesi olan "Bir araya gelmek başlangıçtır, bir arada durabilmek ilerlemedir, birlikte çalışmak başarıdır." sözünün arkasındayız.

TOTEK tarafından bu yıl Uzmanlık Eğitimi Gelişim Sınavı (UEGS)'nın beşincisi gerçekleştirilmiştir. 23. Ulusal Ortopedi ve Travmatoloji Kongresi'nde, TOTEK panelinde dile getirdiğimiz, soru formatı, sonuçların paylaşılması gibi eleştirilerimiz olmakla birlikte, biz asistanlar olarak, verilen eğitimin ölçülmesi ve standardizasyonu için sınavların gerekliliğine inanmaktayız.

\section{EĞіTTM KAYNAKLARI}

Ortopedide eğitim kaynakları, eğitici dersleri, hastaların tedavisi sırasında ameliyathane ve klinik ortamdaki tecrübeleri içerir. Ek bilgiler ise; ortopedik textbooklar ve makaleler okunarak ve internet tabanlı kaynaklardan elde edilmektedir. Biz ortopedi asistanları olarak, mevcut klinik düzenlemeler ve olgu çeşitliliği 
anlamında, klinikler arasında farklılıklar olsa da bu parametreler açısından yurt dışındaki örneklerden geride olduğumuzu düşünmüyoruz. İlerleyen iletişim teknolojileri sayesinde de asistanların bilgiye ulaşımda sorun görülmemektedir.

Yurt dışında son zamanlarda diğer beceri temelli öğrenim olanakları ortopedik cerrahide sıkça kullanılır hale gelmiştir. Bu asistan programlarında, cerrahi beceri laboratuvarlarında, plastik modeller, simülatörler ve kadavralar kullanılarak, asistanların cerrahi teknik ve becerilerinin arttırılması hedeflenmektedir. Ek olarak asistanlar resmi olarak, ortopedi organizasyonlarının, derneklerinin ve firma temelli eğitim ve cerrahi kurslarına asistanlık programının bir parçası olarak katılabilmektedir.

Bu laboratuvarların potansiyel yararının, asistanların cerrahi ekipmanlara, prosedürlere ve tekniğe yatkınlıklarını düşük risk ve maliyet ile arttırmak olduğu düşünülmektedir. ${ }^{[8]}$ Asistanlık eğitimdeki paradigma kayması asistanlar için düşük maliyetli bir şekilde cerrahi yeteneklerini geliştirebilecekleri bu laboratuvarlara yatırım yapılması yönündedir.

Asistanlar bu programlarda, haftada yaklaşık 90 dakika asistanlık eğitiminin resmi bir parçası olarak kadavra diz, omuz, ayak bileği ve dirsek üzerinde artroskopik prosedürlerin pratiğini yapma şansı bulmaktadır. Asistanlar spor cerrahisi rotasyonu sırasında bu pratiklere katılmakla yükümlüdürler. Bu eğitim sırasında bilgilendirme öğretim görevlisi veya spor cerrahinde yan dal yapmakta olan uzman tarafindan verilmektedir. Yine kıdemli asistanlar da, alt kıdemindeki asistanları bilgilendirmekte ve yönlendirmektedir.

Yapılan çalışmalar ve anketler neticesinde simülasyon laboratuvarlarının asistan eğitimdeki önemi vurgulanmaktadır. Ülkemizde de bu eğitim sisteminin rutin uygulamaya dahil edilmesi gerekmektedir.

\section{KURS, KONGRE VE YURT DIŞI EĞiTIM OLANAKLARI}

Ülkemizde TOTBID ve diğer alt dal dernekleri tarafından asistan eğitimine yönelik birçok kurs düzenlenmektedir. Eğiticiler, düzenlenen bu temel bilgi ve beceri kurslarının asistan eğitimine katkısının kongrelere kıyasla daha fazla olduğunu savunmaktadır. Düzenlenen bu kursların başlıcaları Temel Bilimler Araştırma Okulu, Temel Travma Kursu, AO kursu, Temel Artroskopi Kursu, Temel Artroplasti Kursu, ilizarov Kursu, Illeri Travma Kursu, İleri Artroskopi Kursu, İleri Artroplasti Kursu, Temel Omurga Kursu olarak sıralanabilir. TOTBID-AGUH anketine göre bu kurslara en yüksek oranda katılım Temel Bilimler
Araştırma Okulu ve takiben Temel Travma Kursu'nda sağlanmaktadır. Ancak en yüksek katılım oranları bile \%40 dolaylarında kalmıştır. ${ }^{[7]}$ Kurslara katılım konusunda, kaçıncı yıl asistanının katılması gerektiği konusunda önerilerde bulunulmakta ancak bu konunun takibi veya herhangi bir standardı bulunmamaktadır. Organize edilen kurslarda ve kongrelerde asistanlar için indirimli fiyat uygulaması ve burslar asistanlar açısından teşvik edicidir. Katılan asistanların yol ve konaklama ücretlerinin TOTBID tarafından karşılandığı, TOTBID ve TOTEK tarafindan düzenlenen Çekirdek Eğitim Programı Klinik Bilgi Yenileme Kursu buna iyi bir örnek oluşturmaktadır.

Asistanlık eğitimi süresi içerisinde, yurt dışında bir klinikte "fellowship" programları dahilinde, rotasyon şeklinde veya gözlemci olarak bulunulmasının, asistanların başta vizyonların gelişmesi açısından olmak üzere, bireysel gelişimine katkısı aşikardır. Tıpta Uzmanlık Tüzüğünün 22. maddesinde asistanların yurtdışı bir kurumda bir yıla kadar eğitim görmelerine olanak sağlanmıştır. AGUH anketinde ortopedi asistanlarının yurt dışı rotasyon isteği \%95'e yakın olarak bulunmuştur. ${ }^{[7]}$ Ancak asistanlık süresi içerisinde bu yurt dışı eğitim olanaklarından yararlanılmasında, eğitim sorumlusunun bu konudaki vizyonunun, burs olanaklarının etkisi oldukça önemlidir. TOTBiD tarafindan her yıl eylül ve nisan ayında başvuruları alınan ve asistanlar için şartları kolaylaştırılan "yurt dışı araştırma” ve "bilgi pekiştirme" bursları oldukça teşvik edici nitelikte olduğunu düşünüyoruz.

\section{AKADEMIK ÇALIŞMALAR}

Akademik çalışmalarda ve araştırmalarda kendini geliştirmek, asistanın bilgi birikimini arttırmakla beraber, ilerde hangi alanda uzmanlaşmak isteyeceğine dair fikir sahibi olmasını sağlamaktadır. Yıllar boyunca asistanlara verilen bir diğer ortak tavsiye de "Yayınlamazsan unutulur." olmuştur. The American Board of Orthopaedic Surgery, ortopedik cerrahinin gereksinimlerinden biri olarak, asistanların akademik çalışmalar içinde bulunması gerektiğini vurgulamaktadır. ${ }^{[9]}$

Asistanlık eğitimi sırasında hakemli dergilerde yayın üreten bir kişinin bu konudaki birçok becerisini geliştireceği düşünülmektedir. Bu dönemde yayın üreten bir asistanın ilerideki meslek hayatında da bu yayınlara devam edeceği öngörülmektedir. ${ }^{[10]}$

Birçok tıp derneğinin ve eğiticinin de savunduğu görüşe göre; özellikle Sağlık Bakanlığı'na bağlı eğitim hastanelerinde rutin iş yükünün fazlalığı ve eğitime ayrılan sürenin kısalığı nedeniyle, asistanlar bilimsel çaIışmalar için yeterli zamanı bulamamaktadır. Ayrıca, eğitim sorumlusunun bilimsel çalışmalar konusundaki 
isteği ve teşviği, asistanın bu alana yönlendirilmesinde belirleyici olmaktadır. Ingilizce ve istatistik konuları da bilimsel çalışmaların yapılabilmesi için olmazsa olmazlardandır. Tıp fakültesi eğitimi boyunca tıp öğrencisine bu alanlarda gerekli yönlendirmeleri yapan fakülteler olduğu gibi, nispeten daha kısıtlı eğitim veren üniversitelerimiz de mevcuttur.

\section{TARTIŞMA}

Son yıllarda TOTEK ve TOTBID önderliğinde, ülkemizde asistan eğitimin kalitesinin ve standardizasyonunun arttırılmasına yönelik yoğun çalışmalar sürdürülmektedir. Yurtdışındaki eğitim modellerinin değerlendirilip ülkemizde uygulamaya konulması ve asistanların yurtdışı eğitim kurumları ile entegrasyonunun arttırılması bu çalışmalara katkı sağlayacaktır.

\section{KAYNAKLAR}

1. World Federation for Medical Education (WFME). Basic Medical Education. WFME Global Standards for Quality Improvement. Copenhagen: WFME Office; 2003. http:// www.wfme.org Erişim tarihi 10.05.2007.

2. World Federation for Medical Education (WFME). Postgraduate Medical Education. WFME Global Standards for Quality Improvement. Copenhagen: WFME Office; 2003. http://www.wfme.org Erişim tarihi 10.05.2007.
3. World Federation for Medical Education (WFME). Continuing Professional Development (CPD) of Medical Doctors. WFME Global Standards for Quality Improvement. Copenhagen: WFME Office; 2003. http://www.wfme.org Erişim tarihi 10.05.2007.

4. Terzi C. Tıpta Uzmanlık Eğitimi. İçinde: Terzi C, Kutsal A, Yalçın S, Aytaç S, Kocabaş A, Bayındır O, Zorlu P, Özyurt A, Söylemezoğlu $O$, editörler. Türk Tabipleri Birliği Uzmanlık Dernekleri Koordinasyon Kurulu Uzmanlık Dernekleri Rehberi. Ankara: Türk Tabipleri Birliği Yayınları; 2005. s.271-80.

5. Tıpta ve Diş Hekimliğinde Uzmanlık Eğitimi Yönetmeliği. Karar Sayısı : 2009/15153

6. American Board of Orthopaedic Surgery. https://www.abos. org/ Erişim Tarihi: 1 Nisan 2010.

7. Huri G, Şenköylü A, Özkan S, Çabuk YS, Öztuna FV, Aydıngöz Ö. Türkiye'de ortopedi ve travmatoloji asistanlarının uzmanlık eğitiminin değerlendirilmesi: Tanımlayıcı çalışma. Acta Orhop Traumatol Turc 2013; 47 Suppl 1:89.

8. O'neill PJ, Cosgarea AJ, Freedman JA, Queale WS, McFarland EG. Arthroscopic proficiency: a survey of orthopaedic sports medicine fellowship directors and orthopaedic surgery department chairs. Arthroscopy 2002;18(7):795-800.

9. Hurwitz SR. 2012 Rules and Procedures for Residency Education Part I and Part II Examinations. Chapel Hill: American Board of Orthopedic Surgery, Inc.; 2012.

10. Macknin JB, Brown A, Marcus RE. Does research participation make a difference in residency training? Clin Orthop Relat Res 2014;472(1):370-6. CrossRef 